\title{
Improving Laser Beam Welding Efficiency
}

\author{
Mikhail Sokolov ${ }^{1 *}$, Antti Salminen ${ }^{1,2}$ \\ ${ }^{1}$ Laboratory of Laser Materials Processing, Lappeenranta University of Technology, Lappeenranta, Finland \\ ${ }^{2}$ Machine Technology Centre Turku Ltd, Turku, Finland \\ Email: ${ }^{*}$ mikhail.sokolov@lut.fi
}

Received 25 May 2014; revised 30 June 2014; accepted 12 July 2014

Copyright (C) 2014 by authors and Scientific Research Publishing Inc.

This work is licensed under the Creative Commons Attribution International License (CC BY).

http://creativecommons.org/licenses/by/4.0/

c) (i) Open Access

\begin{abstract}
Laser beam welding is becoming widely used in many industrial applications. This paper reviews recent research conducted on the performance, potential and problems of thick section butt joint laser welding. Common defects that occur in laser beam welding with high power laser welding are discussed and possible solutions proposed. Methods of welding process efficiency improvement are analyzed.
\end{abstract}

Keywords

Laser Welding, Edge Preparation, Preheating, Vacuum

\section{Introduction}

Recent developments in the field of high power fiber lasers (HPFL) have led to renewed interest in thick section laser welding. A number of studies have shown that HPFL welding offers the potential for high-speed processing of different metals. The potential of laser beam welding (LBW) of thick sections can be realized in many industrial applications like power plants [1] [2], ship building [3] [4] and pipelines [5]-[7].

\section{Keyhole Welding}

Welding processes imply the following three-steps: melting the metal to form a weld pool on the site of the future joint, permitting the weld pool to grow to the desired size, and maintaining of weld pool stability until solidification. Welding processes may be achieved using different energy sources: from gas flame and electronic arc to electron or laser beam and ultrasound. Of the energy sources used, the laser beam is notable for having the highest power density currently available to industry (up to $10^{9} \mathrm{~W} / \mathrm{cm}^{2}$ ) that is focusable on a small spot (down to $0.1 \mathrm{~mm}$ ) [8]. The absorption of such energy leads not only to material melting but also to evaporation of the material at the point of contact, forming a cylindrical hole in the material which may extend through the entire plate thickness. Over time, the cavity becomes deeper and forms a canal filled with evaporated material along

\footnotetext{
${ }^{*}$ Corresponding author.

How to cite this paper: Sokolov, M. and Salminen, A. (2014) Improving Laser Beam Welding Efficiency. Engineering, 6, 559-571. http://dx.doi.org/10.4236/eng.2014.69057
} 
the direction of the incoming laser beam. The canal, or keyhole, is prevented from closing by the interaction forces of the vapor pressure, the hydrostatic stability of the molten material, and surface tension forces. Five forces should be considered when analyzing the establishment and stability of the keyhole [9]:

1. Pr: recoil pressure, arising from particle evaporation at the surface;

2. Pv: vapor pressure caused by metal vaporization;

3. $\mathrm{Pb}$ : beam pressure, from impinging photons and electrons;

4. Pg: gravitation pressure, in the case of deep keyholes;

5. Ps: surface tension pressure, surface of the keyhole acts like a cylindrical elastic membrane and collapses the keyhole when the energy density falls below a critical level.

As the laser focusing point moves along the joint, a hole is traversed through the material, with the molten walls sealing up behind it [10]. The process and the forces are illustrated in Figure 1.

The laser beam is reflected multiple times on the walls of the keyhole and the molten material of the keyhole walls absorb nearly all the power of the beam. With high welding speed, the process gives a parallel sided fusion zone, narrow weld and high welding efficiency-less energy is spent on unnecessary heat (compared to traditional welding processes). The weld depth may be ten or more times greater than the weld width. The high accuracy and reduced distortion of keyhole welding have made this process common in many applications requiring deeper welds [11].

LBW provides increased processing speed, less post-processing and reduced consumption of materials, leading to increased productivity. The drawbacks of this welding technique are high costs of laser apparatus, difficulty in melting highly reflective or highly thermal-conductive metals, small gap tolerance, and a tendency to the formation of welding defects [12].

Methods to increase the efficiency of the LBW process are an important component of modern deep penetration laser welding research. The purpose of this paper is to review recent research into possible techniques for improving LBW process efficiency.

\section{Laser and Process Efficiencies}

Throughout this paper, the term "efficiency" will refer to LBW process efficiency. However, it is important to first define the term "efficiency" from the perspective of a laser system.

\subsection{Beam Quality}

Applications like thick section welding require high beam quality. Higher beam quality allows focusing of smaller point diameters to achieve very narrow and deep welds. As all modern high power lasers used in thick welding use fibers to deliver the laser beam, the beam quality can be described by Beam Parameter Product (BPP). BPP can be defined as in Equation (1). Beam geometry is shown in Figure 2.

Where:

$$
B P P=\frac{\omega_{0} \theta}{4}
$$

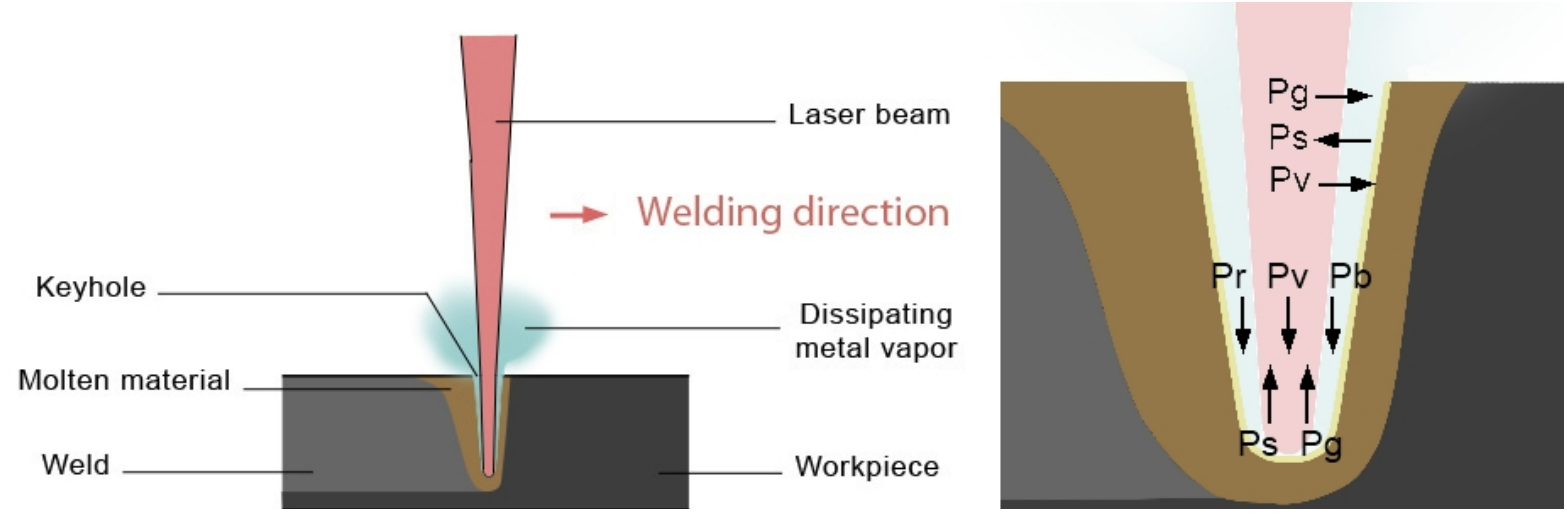

Figure 1. Keyhole welding process and balance of forces of a non-fully penetrating keyhole [9]. 

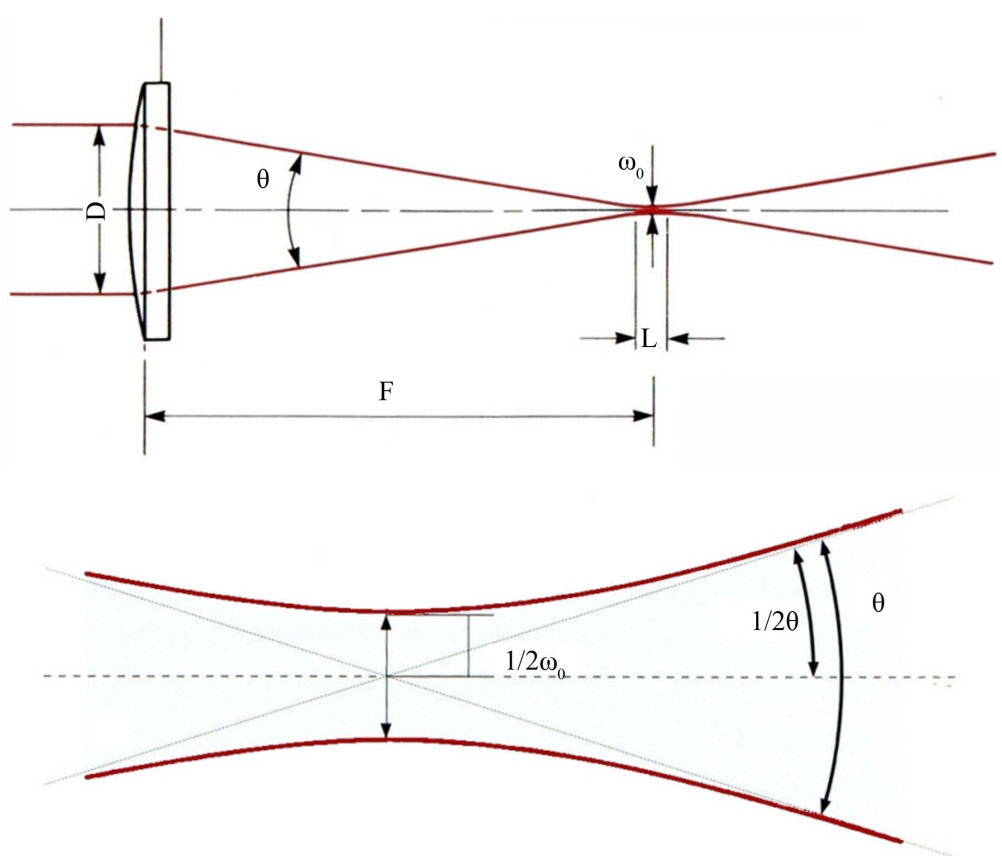

Figure 2. Beam geometry [8].

- $\quad D$ : beam diameter incident on optic, mm;

- $\quad \theta$ : beam convergence angle, degrees;

- $\quad F$ : focal length, mm;

- $\quad L$ : depth of focus, where minimum waist diameter does not increase beyond 5\%, mm;

- $\omega_{0}$ : minimum waist diameter (focus spot size), mm;

- $\lambda$ : wavelength, mm.

In case of using HPFL, the focus spot size depends on the fiber core diameter and the magnification of the optical system. The higher the BBP the smaller spot size can be achieved and the smaller fiber core can be used. Therefore the smaller focus point will be on the workpiece.

\subsection{Laser Electro-Optical Efficiency}

The laser beam is a tool with properties that make it well suited for welding. However, the efficiencies of the conversion of electricity to optical power are limited by the distances where radiated transmission is possible [12] [13].

Dahmen et al. [12] presented an overview of the efficiencies of laser beam sources used in LBW dependent on the beam parameter product, as shown in Figure 3.

Lamp-pumped solid state lasers (LPSSL), for example Nd:YAG, show the lowest efficiency of $4 \%$. Diodepumped solid state lasers (DPSSL) show an efficiency of 15\%. New high power fiber lasers (HPFL) and disc lasers achieve efficiencies of up to $25 \%$. In recent years, due to rapid development of these lasers, the penetration depth and welding speed has been significantly improved [13] [14]. The further analysis of welding process efficiency will refer to HPFL and disc lasers.

\subsection{Welding Process Efficiencies}

There are two dimensionless process efficiencies can be measured as a function of controllable processing variables:

1. $\eta_{a}$ : laser energy transfer efficiency;

2. $\eta_{m}$ : melting efficiency.

The laser energy transfer efficiency is used to describe the ratio of energy that is absorbed by the workpiece over the incident laser energy [15]: 


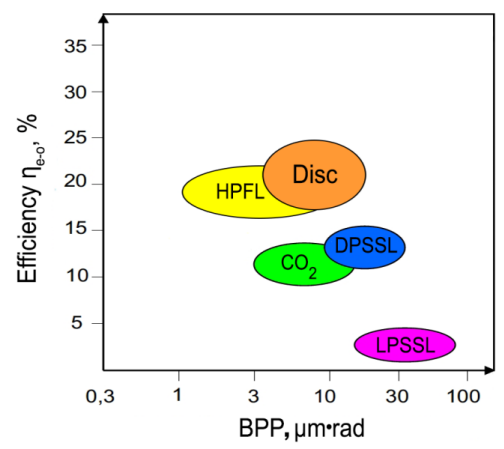

Figure 3. Electro-optical efficiencies of lasers [12].

$$
\eta_{w}=\frac{E_{a}}{P_{L} \cdot t}
$$

where

- $\quad E_{a}$ : total energy absorbed by the workpiece, J;

- $\quad P_{L}$ : laser output power, $\mathrm{W}$ or $\mathrm{J} / \mathrm{s}$;

- $\quad t$ : laser time, $\mathrm{s}$.

The laser energy transfer efficiency is always less than unity because not all of the energy generated by the laser is absorbed by the workpiece.

The second measurable process efficiency is the melting efficiency which is used to describe the amount of energy that is used to create a molten pool from the energy delivered to and absorbed by the workpiece [10]:

$$
\eta_{m}=\frac{V_{W} \cdot T \cdot \omega_{0} \cdot \Delta H_{m}}{P_{L} \cdot t}
$$

where

- $\quad V_{W}$ : welding speed, $\mathrm{m} / \mathrm{s}$;

- $\quad T$ : material thickness, m;

- $\quad P_{L}$ : laser power, $\mathrm{W}$ or $\mathrm{J} / \mathrm{s}$;

- $\quad t$ : laser time, $\mathrm{s}$;

- $\omega_{0}$ : minimum waist diameter, mm;

- $\Delta H_{m}$ : thermal content of the metal at the melt temperature (J).

LBW processing parameters and a number of other factors have a strong effect on the process efficiencies and, therefore, on weld penetration and geometry: laser power, beam diameter, welding speed and focal point position; material physical properties such as laser beam reflectivity, thermal diffusivity, surface tension, content of volatile elements and edge surface roughness; environment conditions such as air, atmosphere pressure, shielding gas type, shielding gas flow rate, laser inducted plasma and plume [16]-[18].

A review of all the possible factors affecting the process efficiency is far beyond the scope of this research. The aim of the paper is to review to most effective solutions thus far reported for improvement of LBW process efficiency.

\subsection{Common Defects in LBW}

Weld quality is an important factor that should be taken into account in analysis of LBW process efficiency. Appropriate choice of process parameters is not a function for maximization of welding process efficiencies, but a search for an acceptable balance between contending factors of physical and metallurgical effects. When this balance is achieved, a high quality weld is accomplished. The reliability of the welded component decreases when there are imperfections or defects in the weld. According to ISO 13919-1 [19] there are three quality levels for weld imperfections: B—stringent; C-intermediate; D—moderate. A list of the most common imperfections found in LBW is given in Table 1 and examples of some defects are illustrated in Figure 4. 


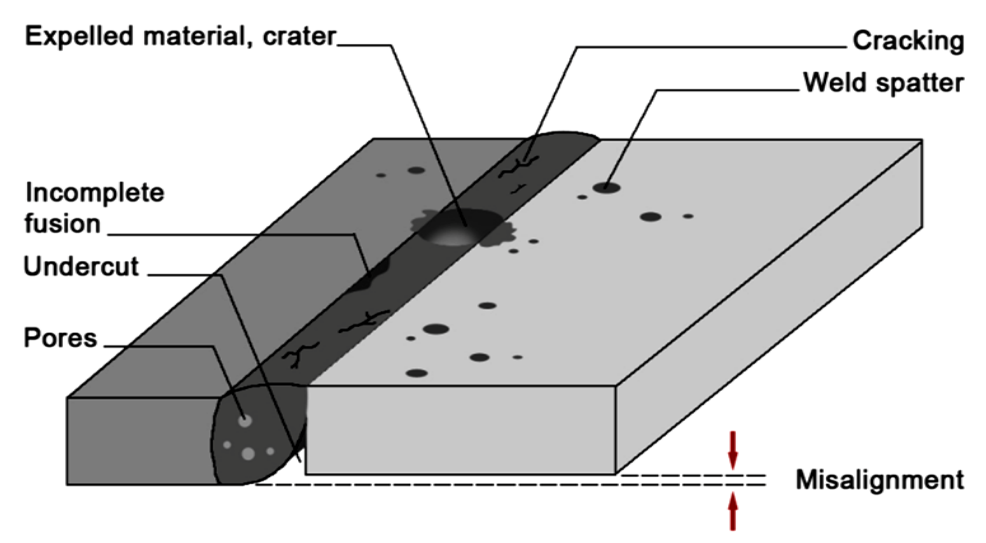

Figure 4. External and internal defects that can occur in butt-joint laser welding [22].

Table 1. Common imperfections in high power laser welding [19]-[21].

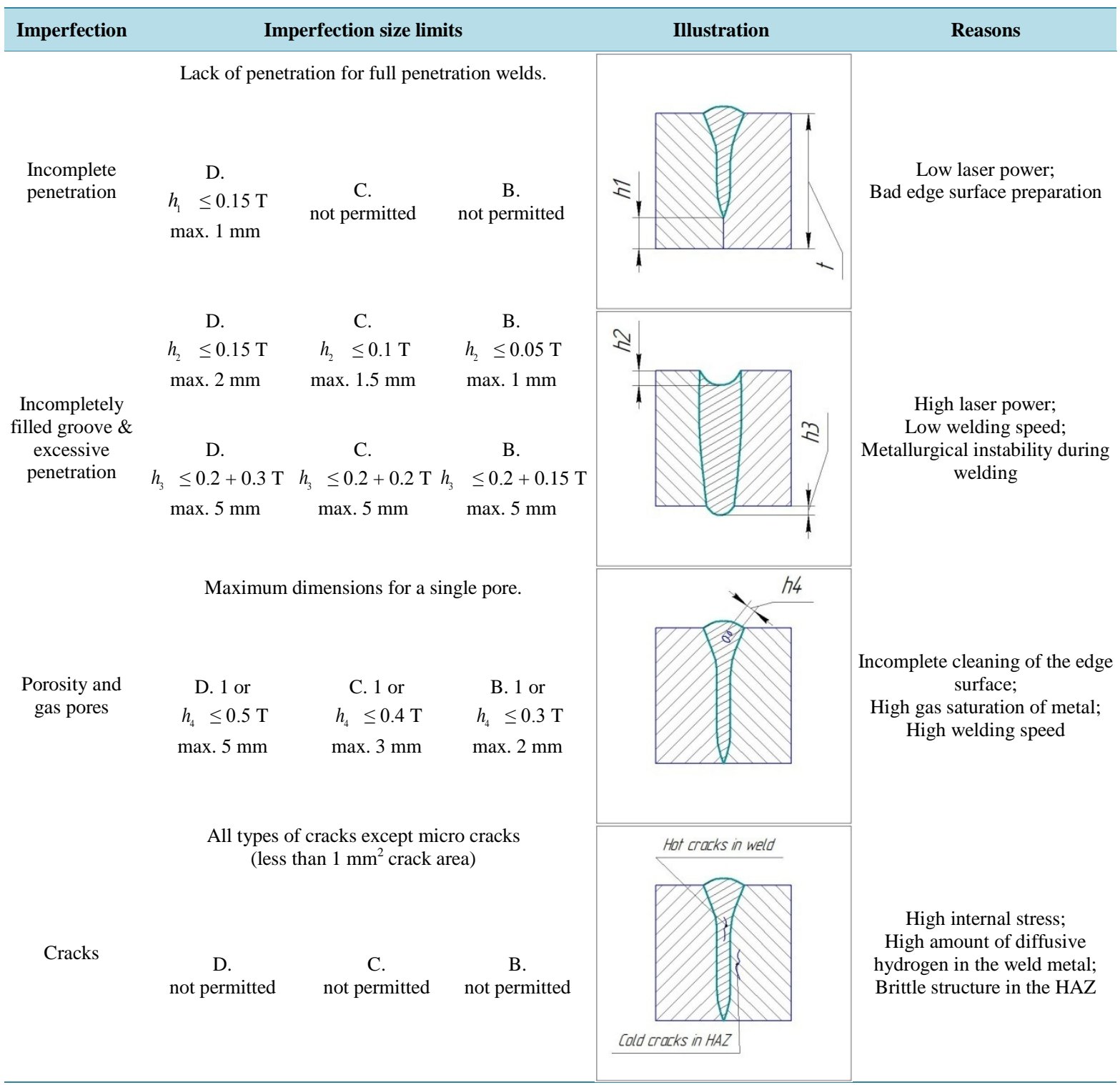


In addition to the defects listed in Table 1, it is important to mention the effect of the specific thermal cycle of thick section high power laser welding. This thermal cycle provides an extremely high rate weld cooling, which causes, in case of welding structural steels, hardening of the material in the HAZ. Around the fusion zone, where the cooling rate is highest, a large increase in the hardness is found [23]. Thick section laser beam welding has lower line energy (down to $5 \mathrm{~J} / \mathrm{mm}$ ) compared with traditional arc welding processes or laser arc hybrid welding, and the highest cooling rates (up to 3000 degrees/second) [8].

Efficiency increasing solutions in the research focus not only on increasing the process efficiency, but also on reducing the probability of defects occurrence.

\subsection{Absorption as the Key to Welding Efficiency}

The absorptance is the fraction of the incident laser light which is absorbed by the workpiece. The absorption level is not a steady factor, but a function of laser and metal properties, listed in Table 2.

There are several different mechanisms of beam absorption by a workpiece. In LBW, where laser energy can deeply penetrate the material via the keyhole, the energy absorption process is described by two mechanisms: Fresnel absorption and inverse Bremsstrahlung absorption. The first mechanism refers to the beam absorption at the solid/liquid surface of the material on the keyhole wall and the second one takes place in the partially ionized plume of vapor in the keyhole. These mechanisms are well described in literature and related articles [8]-[11], [25]-[27]. A number of comparative studies and simulation investigations of Fresnel absorption and multiple reflections in the keyhole have been carried out in recent years. Jin (2008) [28] analyzed factors affecting the keyhole formation and distribution of the laser intensity in the keyhole and noticed that laser energy is not uniformly distributed on the walls of the keyhole, but is concentrated in the region near the front keyhole wall. Kaplan (2012) [29] [30] provides an in-depth analysis of the modulation of the absorption mechanism and influence of surface roughness, wavelength and process parameters on the absorption level.

From Equation (2) it is clear that welding efficiency $\eta_{w}$ can be enhanced if the absorption can be increased. As the possibility of varying the laser parameters is usually limited in workshop conditions, this paper will focus on the material properties listed in Table 2. Based on the literature, absorption improvement methods that can be divided into three groups [8]-[11] [31] [32]:

1. Edge surface modifications;

2. Preheating techniques;

3. Ambient conditions modifications.

\section{Methods to Improve Efficiency}

\subsection{Surface Modifications}

The tendency of increased absorption with increased surface roughness in case of using $\mathrm{CO}_{2}$ laser for low-alloyed steel processing was noted by Arata and Myamoto (1972) [33]. However, this factor has an impact on the absorption level only at the beginning of the welding process; after the stabilization, absorptionno longer depends on the optical properties of the surface.

Analysis of LBW of $4 \mathrm{~mm}$ thickness stainless steel with different edge surface roughness with $2.5 \mathrm{~kW} \mathrm{CO}_{2}$ laser was performed by Covelli (1988) [34]. The tests showed that the properties of the welds were not affected by the surface roughness.

Table 2. Properties influencing absorption [24].

\begin{tabular}{ccc}
\hline Laser Properties & Material Properties & Process Parameters \\
\hline Power density & Composition & Welding speed \\
Wavelength & Temperature & Focal point position \\
Polarization & Roughness & Focal point size \\
Angle of incidence & Surface quality \\
(oxide layers, dust, etc.) & Shielding gas \\
\hline
\end{tabular}


Recent research shows that with use of HPFL, the edge surface roughness has a large effect on absorption, due to the multiple reflection undulations. Bergström et al. (2007) [35] recorded, by reflectance measurements, atrend of increasing absorptance for increasing roughness above Sa $1.5 \mu \mathrm{m}$ for stainless steels and above $6 \mu \mathrm{m}$ for low-alloyed steels. Sokolov et al. [36] [37], using calorimeter absorbed energy measurements, observed a correlation between edge surface roughness and absorption in welding structural steel in a butt-joint setup, as shown on Figure 5. A number of defects were recorded at edge surface roughness exceeding $6.3 \mu \mathrm{m}$.

Modifying surface roughness to improve energy absorption and welding efficiency should not incur additional costs as many manufacturing methods are available and an appropriate method can be selected in accordance with the desired surface roughness, as listed in Table 3.

\subsection{Preheating Techniques}

Preheating of the workpiece improves the LBW process efficiency by modification of the heat conduction characteristics inside the metal. As the temperature of the metal rises, there will be an increase in the photon population, causing more photon-electron energy exchange, as the electrons are more likely to interact with the material rather than oscillate and re-radiate. This phenomenon causes a fall in reflectivity and an increase in the absorptivity with the rise in temperature in the metal and therefore an increase in weld width and depth [27] [39].

Preheating is used to increase the weld width and depth as well as to prevent a number of defects. Changes in material properties due to high cooling rates (2000 - 3000 degrees/second) result in high hardness levelsand a risk

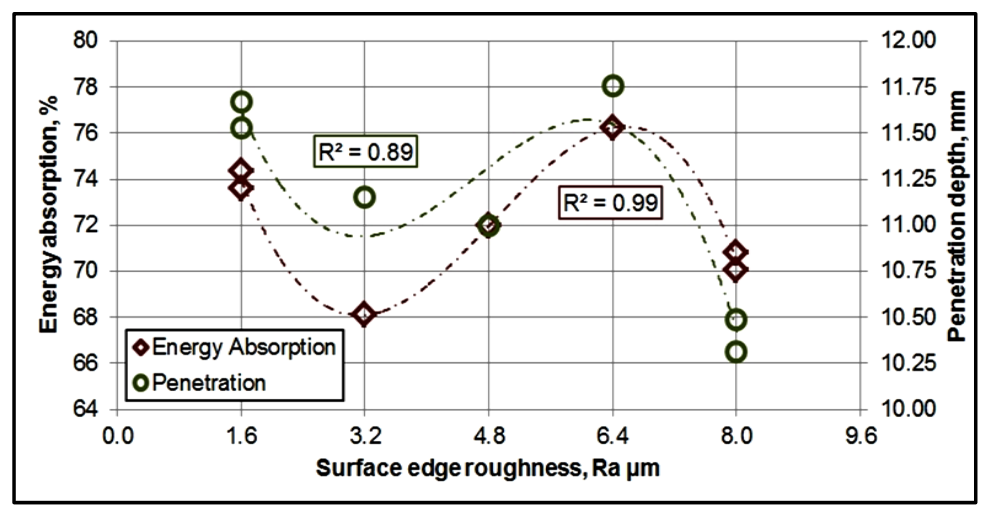

Figure 5. Energy absorption level and penetration depth at different roughness levels, HPFL, low-alloyed steel St 3, $t=20 \mathrm{~mm}, P_{L}=10 \mathrm{~kW}$,

$V_{W}=0.8 \mathrm{~m} / \mathrm{min}, f p p=-4 \mathrm{~mm}, f_{F}=250 \mathrm{~mm}, d_{O F}=420 \mu \mathrm{m}$; Shielding. Ar 20 l/min [36].

Table 3. Example of surface roughness created using common cutting methods [38].

\begin{tabular}{|c|c|c|c|c|c|c|c|}
\hline \multirow{2}{*}{ Cutting method } & \multicolumn{7}{|c|}{ Kerf surface roughness, Ra $\mu \mathrm{m}$} \\
\hline & 50 & 12.5 & 6.3 & 3.2 & 1.6 & 0.8 & 0.4 \\
\hline \multicolumn{8}{|l|}{ Sawing } \\
\hline \multicolumn{8}{|l|}{ Milling } \\
\hline \multicolumn{8}{|l|}{ Flame cutting } \\
\hline \multicolumn{8}{|l|}{ EB cutting } \\
\hline \multicolumn{8}{|l|}{ Laser cutting } \\
\hline Abrasive waterjet & & & & & & & \\
\hline
\end{tabular}

The BLACK sections refer to common and GREEN sections refer to less frequent. 
of cold and hot cracking. The critical cooling time between $800^{\circ}$ and $500^{\circ}$ is very short, so even steel with carbon content lower than $0.2 \%$ tends to form martensitic microstructure in the weld and run a high risk of crack formation [23] [40] [41].

The objective of preheating is to reduce the temperature gradient within the critical temperature range. The optimum preheating temperature depends on many factors: base metal composition, welding speed, workpiece thickness, external temperature, pressure and other environment parameters. In most applications preheating temperature and time are chosen such that the temperature of the workpiece is high enough so that the critical cooling temperature for the specified alloy is not reached. Too high preheating temperature has an adverse effect due to significant changes in the material composition in the HAZ [8] [42]-[44].

Preheating may be performed with the use of additional or splitted laser beams, electric heaters or flame torches - all these methods are proven to help prevent hot cracks and reduce hardness. However, the drawback of the above-mentioned techniques is the method of energy input: heat energy has to be transferred via the top surface of the weld, while hot-sensitive areas are situated several millimeters below the surface. In this situation, overheating of the top surface is very possible [45] [46].

Use of multi-beam welding techniques or dynamic beam forming to lower cooling rates, reduce volume percent martensite and therefore reduce hardness has been investigated in the last decade. A number of studies indicate a positive solution to the cracking problem in LBW [47]-[49]. Katayama, 2011 [50] utilized a twin beam method, using two laser sources as shown in Figure 6, whereas other authors (Xie, 2002 [51], Blackburn, 2010 [52]) utilized one laser source with a dual focus forming module or beam splitting system as shown in Figure 7.

In dynamic beam forming techniques mirrors deflect the focused laser beam and a mirror rotation of a few degrees causes laser beam to move several centimeters as shown on Figure 8. Oscillating mirrors, operating HPFL beams, are made of coated copper, or coated aluminum with water-cooling systems and are used in case of a small gap and less accurate geometry tolerances in butt-joint setups and allows widening of the weld, changing the focal point size or pattern. Vänskä and Salminen, 2012 [53] reported a successful adoption of beam forming techniques in tube-to-tube joints. Kraetzsch et al., 2011 [54] pointed to ways of utilizing the laser beam oscillation for controlling weld seam geometry, meld pool turbulence and solidification behavior in welding of dissimilar materials.

In recent years, LBW has been assisted by induction heating. In induction preheating, low and medium frequency induction coils are heating the whole workpiece or move with the laser beam to achieve a constant effect of the critical cooling zones. For a butt-joint configuration a combination of two-armed induction coils were used by Göbel and Brener [46] (2006) to heat both sides of the weld, as shown in Figure 9.

The temperature field tailoring and reduction if tensile stresses possible with induction assisted LBW have

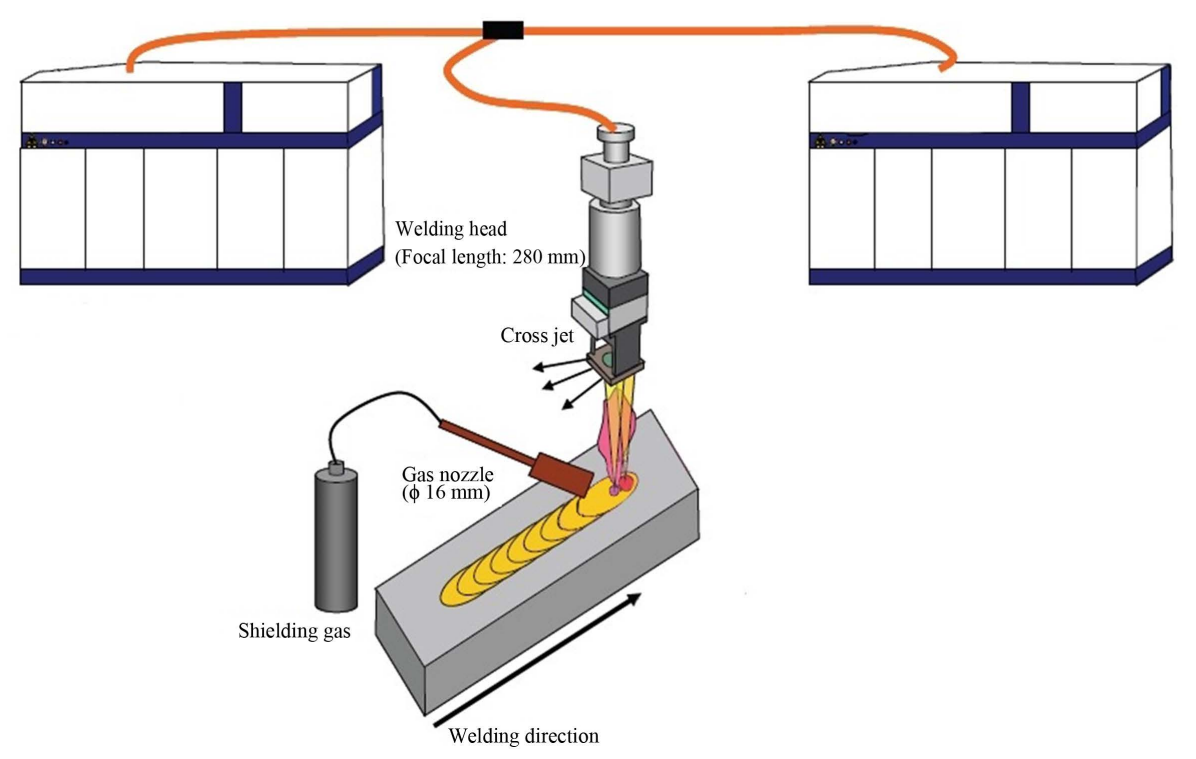

Figure 6. Twin of tandem beam system schematics [50]. 


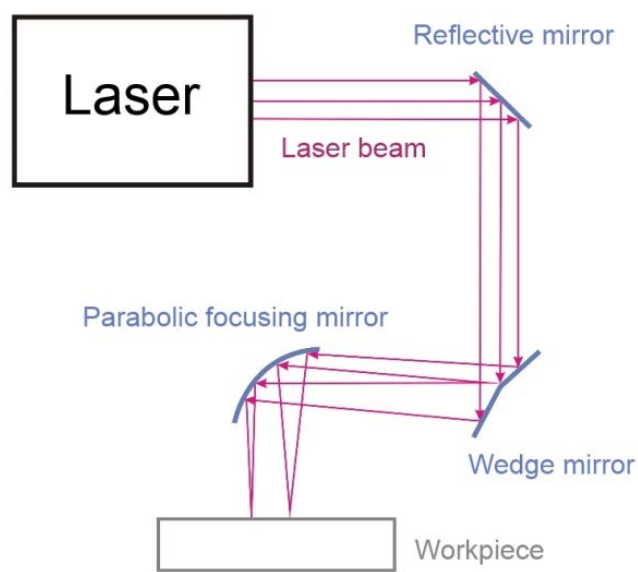

Figure 7. Beam splitting system schematics [51].

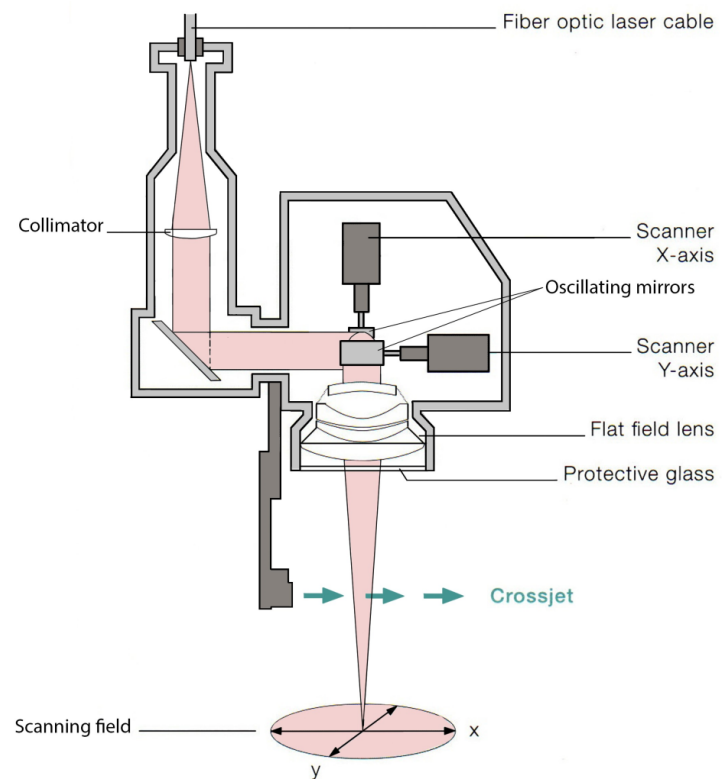

Figure 8. Dynamic beam forming techniques principle [22].

proved useful in avoiding hot cracks and other common defects, as well as being a relatively cost effective method compared to laser based beam splitting or scanning techniques [41] [46] [55].

\subsection{Ambient Conditions Modifications}

Katayama et al. 2001 [31] highlighted the potential for reduced pressure laser welding with a high-power. In later experiments with stainless steel, Katayama et al. 2011 [56] with a laser power up to $26 \mathrm{~kW}$ achieved an acceptable quality weld of $75 \mathrm{~mm}$ penetration depth with a $1 \mathrm{~m} / \mathrm{min}$ speed single pass LBW at $1 \mathrm{kPa}$ pressure. To achieve the desired pressure level, a vacuum chamber was sealed up, and the pressure was lowered by three rotary pumps. This method has certain limitations by size of the workpiece and use of the method in industry, as the welding process time have to be increased significantly.

Blackburn et al. (2013) [32] using a $5 \mathrm{~kW}$ Yb-fibre laser at reduced pressure achieved $11 \mathrm{~mm}$ penetration at a welding speed of $1 \mathrm{~m} / \mathrm{min}$ using a sliding vacuum seal, illustrated in Figure 10.

Yang et al. (2013) [57] used more simple application of vacuum-assisted welding for zinc-coated steels: negative pressure zone is created directly on the top of the molten pool during the laser welding process by removal of the laser-induced plasma and plume enhances via copper tube installed on the top of the welding as shown in Figure 11. 


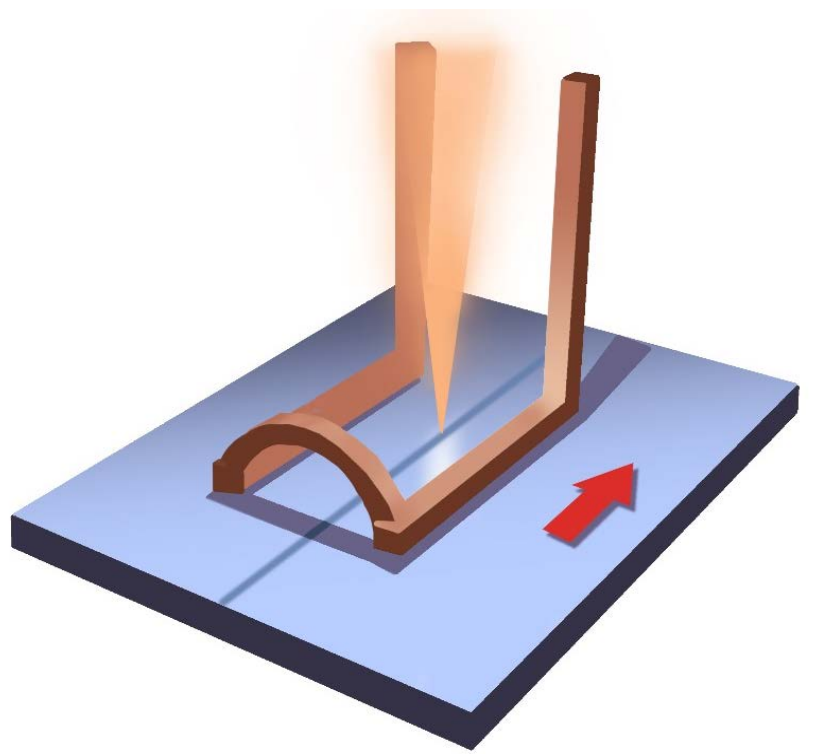

Figure 9. Inductive heating around the weld in butt-joint setup [46].

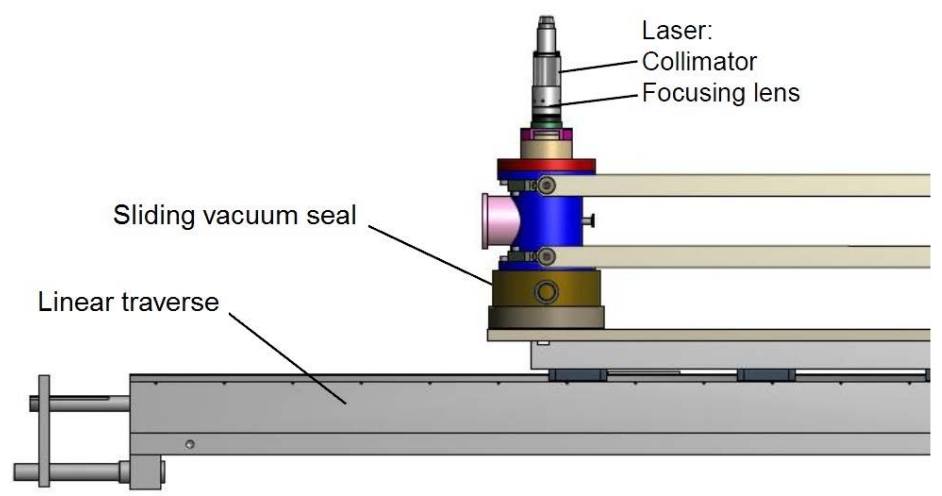

Figure 10. Schematic of a prototype sliding seal vacuum chamber, developed by TWI [32].

Significant increase in penetration depth (up to 200\%) [32] as well as quality improvement compared with welding under atmospheric pressure [56]. Although this technology requires additional equipment and increase the preparation time, further research in this field would be of great help in improvement of LBW efficiency.

\section{Conclusions}

The present study was designed to review up-to-date methods for LBW of steels with HPFLs. The following conclusions can be drawn from the study:

1. LBW efficiency improvement can be achieved by increase in absorption.

2. There are three basic ways to improve LBW efficiency: by modifying the workpiece through surface preparation; by modifying the process with preheating or by lowering the pressure in the welding zone.

3. In thick section LBW at high power levels $(\geq 10 \mathrm{~kW})$ absorption has a significant dependence on the edge surface roughness. The influence of the roughness level has a tendency to increase with increasing laser power. Use of manufacturing methods that produce edge surfaces of a pre-determined roughness level is recommended.

4. Preheating techniques are preferable not only because of the resulting increase in process efficiency, but also because of reduction in the occurrence risk of defects.

5. Vacuum-assisted welding provides significant increase in penetration depth and weld quality. 


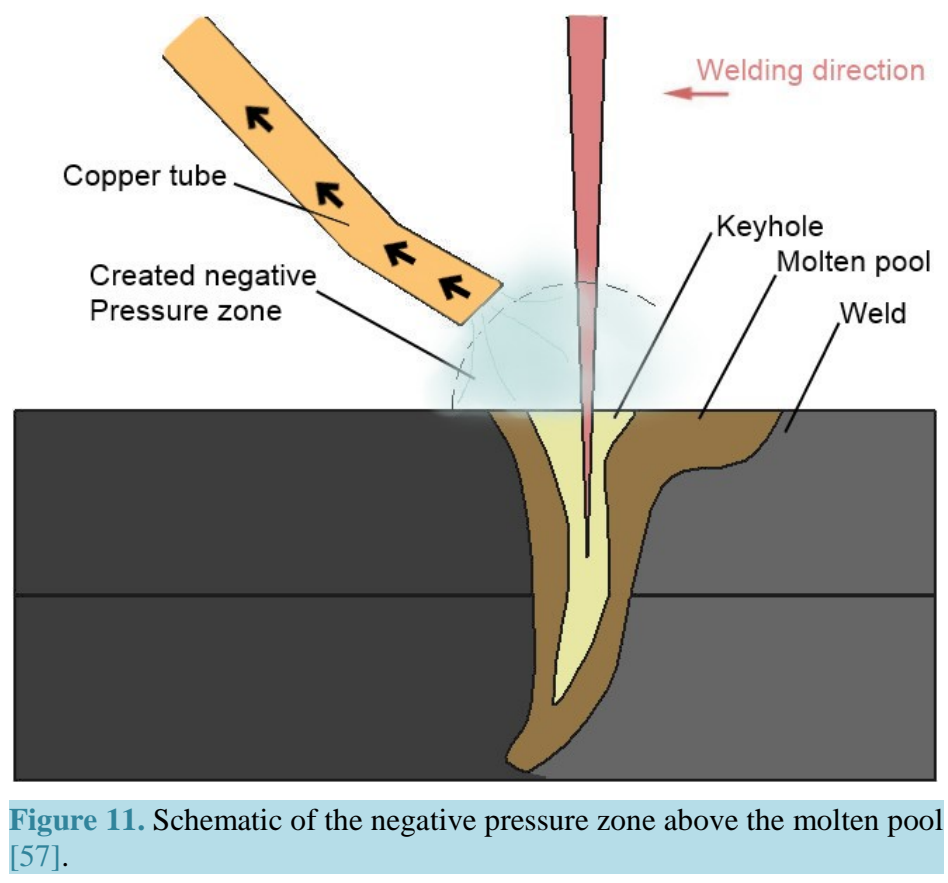

6. Several described above methods may be used together to promote an additional increase in the absorption and, therefore, efficiency. The relationships and causalities of these factors require further investigation.

\section{Acknowledgements}

This article was written as part of the Finnish Metals and Engineering Competence Cluster (FIMECC)'s Innovation \& Network program.

\section{References}

[1] Shimokusu, Y., Fukumoto, S., Nayama, M., Ishide, T. and Tsubota, S. (2001) Application of High Power YAG Laser Welding to Stainless Steel Tanks, Mitsubishi Heavy Industries, Ltd. Technical Review, 38, 118-121.

[2] Ishide, T., Tsubota, S., Nayama, M., Shimokusu, Y., Nagashima, T. and Okimura, K. (2000) 10-kW-Class YAG Laser Application for Heavy Components. In: Chen, X.L., Fujioka, T., Matsunawa, A., Eds., Advanced High-Power Lasers and Applications, Society of Photo Optical, 543-550.

[3] Roland, F., Reinert, T. and Pethan, G. (2003) Laser Welding in Shipbuilding-An Overview of the Activities at Meyer Werft. Welding Research Abroad, 49, 39-51.

[4] Tsirkas, S.A., Papanikos, P., Pericleous, K., Strusevich, N., Boitout, F. and Bergheau, J.M. (2003) Evaluation of Distortions in Laser Welded Shipbuilding Parts Using Local-Global Finite Element Approach. Science and Technology of Welding \& Joining, 8, 79-88. http://dx.doi.org/10.1179/136217103225010899

[5] Moore, P.L., Howse, D.S. and Wallach, E.R. (2004) Microstructures and Properties of Laser/Arc Hybrid Welds and Autogenous Laser Welds in Pipeline Steels. Science and Technology of Welding \& Joining, 9, 314-322. http://dx.doi.org/10.1179/136217104225021652

[6] Yapp, D. and Blackman, S.A. (2004) Recent Developments in High Productivity Pipeline Welding. Journal of Brazilian Society of Mechanical Science and Engineering, 26, 89-97. http://dx.doi.org/10.1590/S1678-58782004000100015

[7] Hecht, J. (2009) Fiber Lasers Ramp up the Power. Laser Focus World, 45, 53-57.

[8] Dawes, C. (1992) Laser Welding: A Practical Guide. Redwood Press Ltd, Cambridge. http://dx.doi.org/10.1533/9781845698843

[9] Lancaster, J.F. (1984) The Physics of Welding. Pergamon Press, Oxford.

[10] Duley, W.W. (1998) Laser Welding. John Wiley \& Sons Inc., New York.

[11] Ion, J.C. (2005) Laser Processing of Engineering Materials. Biddles Ltd., Norfolk.

[12] Dahmen, M., Güdükkurt, O. and Kaierle, S. (2010) The Ecological Footprint of Laser Beam Welding. Physics Proce- 
dia, 5, 19-28. http://dx.doi.org/10.1016/j.phpro.2010.08.025

[13] Barnes, N.P. (2007) Solid-State Lasers from an Efficiency Perspective. IEEE Journal of Selected Topics in Quantum Electronics, 13, 435-447.

[14] Zhang, X., Ashida, E., Tarasawa, S., Anma, Y., Okada, M., Katayama, S. and Mizutani, M. (2011) Welding of Thick Stainless Steel Plates up to 50 mm with High Brightness Lasers. Journal of Laser Applications, 23, Article No. 022002. http://dx.doi.org/10.2351/1.3567961

[15] Unocic, R.R. and DuPont, J.N. (2004) Process Efficiency Measurements in the Laser Engineered Net Shaping Process. Metallurgical and Material Transactions B, 35, 143-152.

[16] Katayama, S., Kawahito, Y. and Mizutani, M. (2010) Elucidation of Laser Welding Phenomena and Factors Affecting Weld Penetration and Welding Defects. Physics Procedia, 5, 9-17. http://dx.doi.org/10.1016/j.phpro.2010.08.024

[17] Salminen, A., Piili, H. and Purtonen, T. (2010) The Characteristics of High Power Fibre Laser Welding. Proceeding of the Institution of Mechanical Engineers Part C: Journal of Mechanical Engineering Science, 224, 1019-1029. http://dx.doi.org/10.1243/09544062JMES1762

[18] Zhang, M., Chen, G., Zhou, Y. and Liao, S. (2013) Optimization of Deep Penetration Laser Welding of Thick Stainless Steel with a $10 \mathrm{~kW}$ Fiber Laser. Materials \& Design, 53, 568-576.

[19] ISO 13919-1 (1996) Welding. Electrons and Laser Beam Welded Joints. Guidance on Quality Levels for Imperfections. Part 1: Steel.

[20] EN 10025-1 (2004) Hot Rolled Products of Structural Steels. Part 1: General Technical Delivery Conditions.

[21] EN 10025-2 (2004) Hot Rolled Products of Structural Steels. Part 2: Technical Delivery Condition for Non-Alloy Structural Steels.

[22] TRUMPF Group (2007) The Laser As a Tool. Vogel Buchverlag, Würzburg.

[23] Sokolov, M., Salminen, A., Kuznetsov, M. and Tsibulskiy, I. (2011) Laser Welding and Weld Hardness Analysis of Thick Section S355 Structural Steel. Materials \& Design, 32, 5127-5131. http://dx.doi.org/10.1016/j.matdes.2011.05.053

[24] Bergström, D. (2005) The Absorptance of Metallic Alloys to Nd:YAG and Nd:YLF Laser Light. Doctoral Dissertation, Luleå University of Technology, Luleå.

[25] Li, L. (2008) Lasers in Technology, Physical Methods. Instruments and Measurements, 4, 159-173.

[26] Hagen, E. and Rubens, H. (1904) Emissivity and Electrical Conductivity of Alloys. Deutsche Physikalische Gesellschaft, 6, 128-136.

[27] Steen, W.M. (2003) Laser Material Processing. 3rd Edition, Springer-Verlag, London. http://dx.doi.org/10.1007/978-1-4471-3752-8

[28] Jin, X. (2008) A Three-Dimensional Model of Multiple Reflections for High-Speed Deep Penetration Laser Welding Based on an Actual Keyhole. Optics and Lasers in Engineering, 46, 83-93. http://dx.doi.org/10.1016/j.optlaseng.2007.05.009

[29] Kaplan, A.F.H. (2012) Fresnel Absorption of $1 \mu \mathrm{m}$ - and $10 \mu \mathrm{m}$-Laser Beams at the Keyhole Wall during Laser Beam Welding: Comparison between Smooth and Wavy Surfaces. Applied Surface Science, 258, 3354-3363. http://dx.doi.org/10.1016/j.apsusc.2011.08.086

[30] Kaplan, A.F.H. (2012) Local Absorptivity Modulation of a $1 \mu \mathrm{m}$-Laser Beam through Surface Waviness. Applied Surface Science, 258, 9732-9736. http://dx.doi.org/10.1016/j.apsusc.2012.06.020

[31] Katayama, S., Kobayashi, Y., Mizutani, M. and Matsunawa, A. (2001) Effect of Vacuum on Penetration and Defects in Laser Welding. Journal of Laser Applications, 13, 187. http://dx.doi.org/10.2351/1.1404413

[32] Blackburn, J., Allen, C., Smith, S. and Hilton, P. (2013) Thick-Section Laser Welding. Proceeding of LAMP2013, the 6th International Congress on Laser Advanced Material Processing, Niigata, 23-26 July 2013.

[33] Arata, Y. and Miyamoto, I. (1972) Some Fundamental Properties of High Power Laser Beam as a Heat Source (Report 2). Transactions of the Japan Welding Society, 3, 152-162.

[34] Covelli, L., Jovane, F., De lorio, L. and Tagliaferri, V. (1988) Laser Welding of Stainless Steel: Influence of the Edges Morphology. CIRP Annals, Manufacturing Technology, 37, 545-548.

[35] Bergström, D., Powell, J. and Kaplan, A.F.H. (2007) The Absorptance of Steels to Nd:YLF and Nd:YAG Laser Light at Room Temperature. Applied Surface Science, 253, 5017-5028. http://dx.doi.org/10.1016/j.apsusc.2006.11.018

[36] Sokolov, M., Salminen, A., Somonov, V. and Kaplan, A.F. (2012) Laser Welding of Structural Steels: Influence of the Edge Roughness Level. Optics \& Laser Technology, 44, 2064-2071. http://dx.doi.org/10.1016/j.optlastec.2012.03.025

[37] Sokolov, M. and Salminen, A. (2012) Experimental Investigation of the Influence of Edge Morphology in High Power Fiber Laser Welding. Physics Procedia, 39, 33-42. http://dx.doi.org/10.1016/j.phpro.2012.10.011 
[38] Degarmo, E.P., Black, J.T. and Kosher, R.A. (2003) Materials and Processes in Manufacturing. 9th Edition, Wiley, Hoboken.

[39] Peretz, R. (1988) The Preheating Temperature Parameter for Deep Penetration Welding with High Energy Focused Beams. Optics and Lasers in Engineering, 9, 23-34. http://dx.doi.org/10.1016/0143-8166(88)90026-7

[40] Akesson, B. and Karlsson, L. (1976) Prevention of Hot Cracking of Butt Welds in Steel Panels by Controlled Additional Heating of the Panels. Welding Research International, 6, 35-52.

[41] Rosenfeld, R., Herzog, D. and Haferkamp, H. (2009) Process Combination of Laser Welding and Induction Hardening. Proceeding of the 5th International WLT-Conference on Lasers in Manufacturing, Munich, 15-18 June 2009, 71-75.

[42] Miranda, R., Costa, A., Quintino, L., Yapp, D. and Iordachescu, D. (2009) Characterization of Fiber Laser Welds in X100 Pipeline Steel. Materials \& Design, 30, 2701-2707. http://dx.doi.org/10.1016/j.matdes.2008.09.042

[43] Hu, L.H., Huang, J., Li, Z.G. and Wu, Y.X. (2011) Effects of Preheating Temperature on Cold Cracks, Microstructures and Properties of High Power Laser Hybrid Welded 10Ni3CrMoV Steel. Materials \& Design, 32, 1931-1939. http://dx.doi.org/10.1016/j.matdes.2010.12.007

[44] Böllinghaus, T. and Herold, H. (2005) Hot Cracking Phenomena in Welds. Springer-Verlag Berlin Heidelberg, Berlin. http://dx.doi.org/10.1007/b139103

[45] Yang, S. and Kovacevic, R. (2009) Laser Welding of Galvanized DP980 Steel Assisted by the GTAW Preheating in a Gap-Free Lap Joint Configuration. Journal of Laser Applications, 21, 139-148. http://dx.doi.org/10.2351/1.3184432

[46] Göbel, G. and Brenner, B. (2006) Avoiding Hot Cracking by Induction Based Change of Thermal Strains during Laser Welding. Proceedings of 25th International Congress on Applications of Lasers \& Electro Optics ICALEO, 34-43.

[47] Iqbal, S. and Gualini, M. (2010) Dual Beam Method for Laser Welding of Galvanized Steel: Experimentation and Prospects. Optics \& Laser Technology, 42, 93-98. http://dx.doi.org/10.1016/j.optlastec.2009.05.009

[48] Ploshikhin, V., Prikhodovsky, A., Makhutin, M., Zoch, H.W., Heimerdinger, C. and Palm, F. (2004) Multi-Beam Welding: Advanced Technique for Crack-Free Laser Welding. Proceedings of 4th International Conference Laser Assisted Net Shape Engineering LANE, Erlangen, 21-24 September 2004, 131-136.

[49] Liu, Y.N. and Kannatey-Asibu Jr., E. (1997) Experimental Study of Dual-Beam Laser Welding of AISI 4140 Steel. Welding Journal, 76, 342-348.

[50] Katayma, S., Hirayama, M., Mizutani, M. and Kawahito, Y. (2011) Deep Penetration Welds and Welding Phenomena with Combined Disk Lasers. Proceedings of 30th International Congress on Applications of Lasers \& Electro Optics ICALEO, Orlando, 23-27 October 2011, 661-668.

[51] Xie, J. (2002) Dual Beam Laser Welding. Welding Journal, 81, 223-230.

[52] Blackburn, J., Allen, C., Smith, S., Punshon, C. and Hilton, P. (2010) Dual Focus Nd: YAG Laser Welding of Titanium Alloys. Proceedings of the 36th International MATADOR Conference, Manchester, 14-16 July 2010, $279-282$. http://dx.doi.org/10.1007/978-1-84996-432-6_64

[53] Vänskä, M. and Salminen, A. (2012) Laser Welding of Stainless Steel Self-Steering Tube-to-Tube Joints with Oscillating Mirror. Proceedings of the Institute of Mechanical Engineering, Part B: Journal of Engineering Manufacture, 226, 632-640. http://dx.doi.org/10.1177/0954405411425114

[54] Kraetzsch, M., Standfuss, J., Klotzbach, A., Kaspar, J., Brenner, B. and Beyer, E. (2011) Laser Beam Welding with High-Frequency Beam Oscillation: Welding of Dissimilar Materials with Brilliant Fiber Lasers. Physics Procedia, 12, 142-149. http://dx.doi.org/10.1016/j.phpro.2011.03.018

[55] Brenner, B., Standfuss, J., Wetzig, A., Fux, V., Lepski, D. and Beyer, E. (1998) New Developments in Induction Assisted Laser Materials Processing. European Conference on Laser Treatment of Materials, Hanover, 22-23 September 1998, 57-66.

[56] Katayama, S., Yohei, A., Mizutani, M. and Kawahito, Y. (2011) Development of Deep Penetration Welding Technology with High Brightness Laser under Vacuum. Physics Procedia, 12, 75-80. http://dx.doi.org/10.1016/j.phpro.2011.03.010

[57] Yang, S., Wang, J., Carlson, B. and Zhang, J. (2013) Vacuum-Assisted Laser Welding of Zinc-Coated Steels in a GapFree Lap Joint Configuration. Welding Journal, 92, 197-204. 
Scientific Research Publishing (SCIRP) is one of the largest Open Access journal publishers. It is currently publishing more than 200 open access, online, peer-reviewed journals covering a wide range of academic disciplines. SCIRP serves the worldwide academic communities and contributes to the progress and application of science with its publication.

Other selected journals from SCIRP are listed as below. Submit your manuscript to us via either submit@scirp.org or Online Submission Portal.
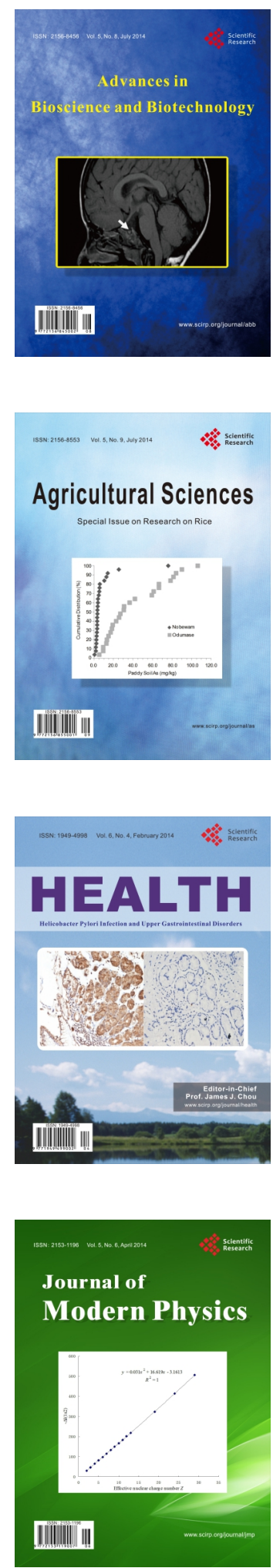
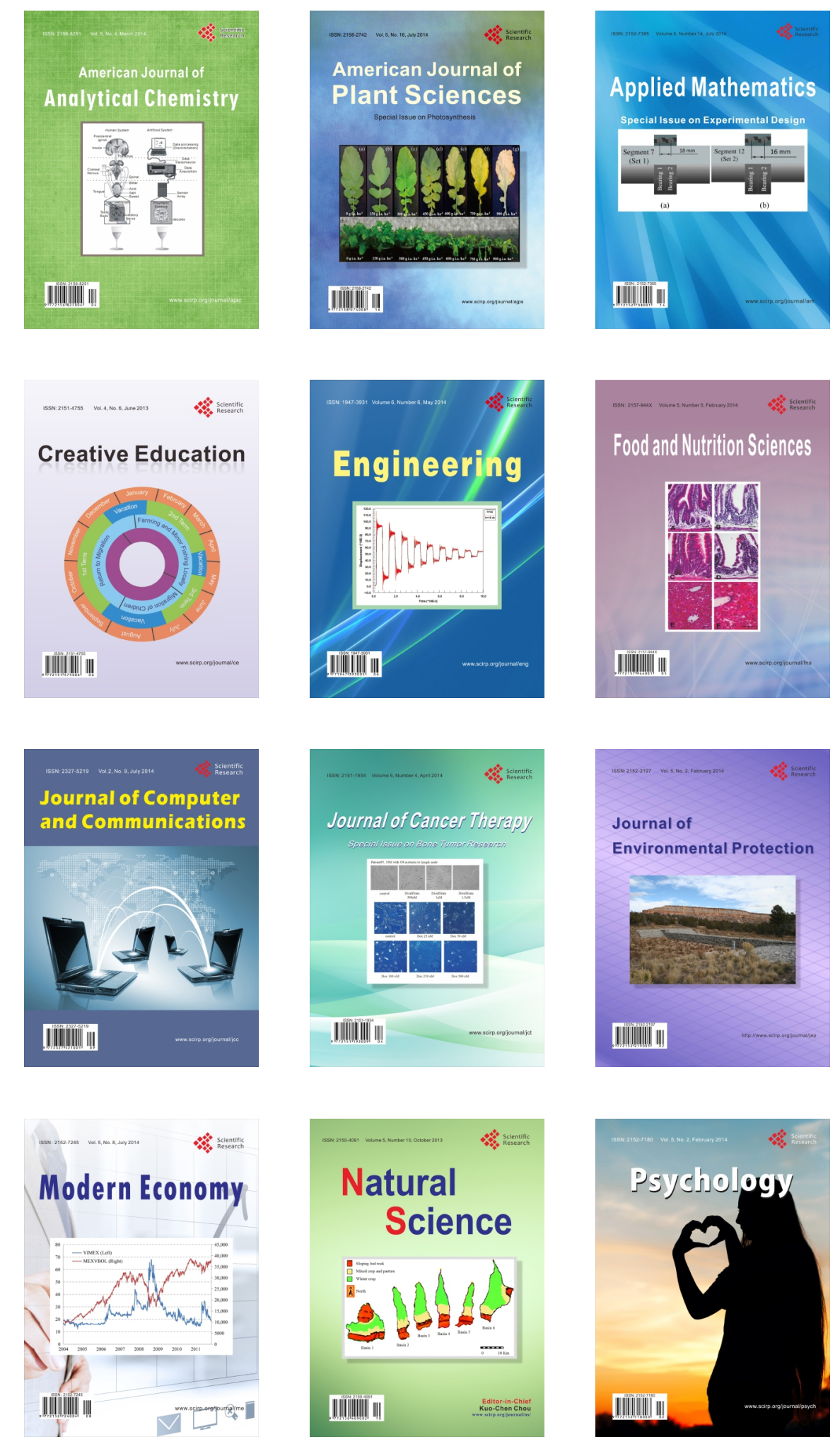